\title{
Inhibitory Mechanisms of Flavonoids on Insulin-Stimulated Glucose Uptake in MC3T3-G2/PA6 Adipose Cells
}

\author{
Masaaki Nomura, ${ }^{a}$ Tatsuo TaKahashi,${ }^{a}$ Naoto Nagata, ${ }^{b}$ Kikue Tsutsumi, ${ }^{b}$ Shinjiro Kobayashi,${ }^{a, c}$ \\ Tetsuo Akiba, ${ }^{d}$ Koichi Yokogawa, ${ }^{b, d}$ Shuzo Moritani, ${ }^{e}$ and Ken-ichi MiYamoto ${ }^{*, b, d}$ \\ ${ }^{a}$ Department of Clinical Pharmacology, Faculty of Pharmaceutical Sciences, Hokuriku University; ${ }^{c}$ Organization for \\ Frontier Research in Preventive Pharmaceutical Sciences, Hokuriku University; Kanazawa 920-1181, Japan: \\ ${ }^{b}$ Department of Hospital Pharmacy, School of Medicine, Kanazawa University; ${ }^{d}$ Department of Medicinal Informatics, \\ Graduate School of Medical Science, Kanazawa University; 13-1 Takara-machi, Kanazawa 920-8641, Japan: and \\ ${ }^{e}$ Department of Nursing, Faculty of Nursing and Welfare, Fukui Prefectural University; Fukui 910-1195, Japan. \\ Received March 11, 2008; accepted April 24, 2008; published online May 9, 2008
}

We assessed the effects of different classes of flavonoids on insulin-stimulated 2 -deoxy-D-[1- $\left.{ }^{3} \mathrm{H}\right] \mathrm{glucose}$ uptake by mouse MC3T3-G2/PA6 cells differentiated into mature adipose cells. Among the flavonoids examined, the flavones, apigenin and luteolin, the flavonols, kaempferol, quercetin and fisetin, an isoflavone, genistein, a flavanonol, silybin, and the flavanols, (-)-epigallocatechin gallate (EGCG) and theaflavins, significantly inhibited insulin-stimulated glucose uptake. Key structural features of flavonoids for inhibition of insulin-stimulated glucose uptake are the B-ring $4^{\prime}$ - or $3^{\prime}, 4^{\prime}-\mathrm{OH}$ group and the $\mathrm{C}$-ring $\mathrm{C} 2-\mathrm{C} 3$ double bond of the flavones and flavonols, the A-ring 5-OH of isoflavones, and the galloyl group of EGCG and theaflavins. Luteolin significantly inhibits insulin-stimulated phosphorylation of insulin receptor- $\beta$ subunit (IR- $\beta$ ), and apigenin, kaempferol, quercetin and fisetin, also tended to inhibit the IR- $\beta$ phosphorylation. On the other hand, isoflavones, flavanols or flavanonols did not affect insulin-stimulated IR- $\beta$ phosphorylation. Apigenin, luteolin, kaempferol, quercetin and fisetin also appeared to inhibit insulin-stimulated activation of Akt, a pivotal downstream effector of phosphatidylinositol 3-kinase (PI3K), and suppressed insulin-dependent translocation of a glucose transporter, (GLUT)4, into the plasma membrane. Although genistein, silybin, EGCG and theaflavins had no effect on the insulin-stimulated activation of Akt, they blocked insulin-dependent GLUT4 translocation. These results provide novel insights into the modulation by flavonoids of insulin's actions, including glucose uptake in adipocytes.

Key words flavonoid; adipocyte; glucose uptake; insulin; Akt; glucose transporter 4

Insulin plays a key role in the stimulation of glucose uptake in tissues, such as muscle and adipocytes, as well as in the maintenance of glucose homeostasis. Impairment of insulin's ability to stimulate glucose uptake in the tissues is a major factor responsible for insulin resistance associated with type 2 diabetes. ${ }^{1)}$ The primary mechanism of insulinstimulated glucose uptake in muscle and adipocytes is through the translocation of glucose transporter 4 (GLUT4) from intracellular pools to the plasma membrane. ${ }^{2)}$ Insulin signal transduction is initiated by binding to the insulin receptor, followed by activation of the receptor tyrosine kinase (RTK). ${ }^{3,4)}$ The activated RTK induces activation of downstream signaling pathways, such as phosphatidylinositol 3-kinase (PI3K) and mitogen-activated protein kinase (MAPK) pathways. The translocation of GLUT4 to the plasma membrane was established to be mediated through the PI3K pathway, based on the use of pharmacological inhibitors, and expression of a dominant negative mutant or constitutively active form of PI3K. ${ }^{5-9)}$

Flavonoids, which are primarily phenylbenzo- $\gamma$-pyrone (phenylchromone) derivatives, are polyphenolic compounds present in fruits, vegetables, and beverages. ${ }^{10)}$ It has been reported that flavonoids possess a variety of biological activities, including anti-inflammatory, anti-oxidant, anti-bacterial, anti-cardiovascular disease, and anti-cancer activities. ${ }^{11)}$ These actions were suggested to result from changes in the activity of a number of intracellular enzymes, including tyrosine kinases, protein kinase $\mathrm{C}, \mathrm{PI} 3 \mathrm{~K}$, and MAPK. ${ }^{11-14)}$ The findings suggest that flavonoids may modify insulin-stimulated glucose uptake by modulating insulin RTK and/or PI3K activity in muscle or adipose cells. Indeed, several reports have shown that flavonoids, such as myricetin, quercetin, catechin-gallate, genistein, and naringenin, inhibited insulinstimulated glucose uptake in adipocytes. ${ }^{15-17)}$ However, the inhibitory mechanisms may be different for flavonoids of different classes or structures. Bazuine et $a l .{ }^{15)}$ reported that genistein, an isoflavone, directly inhibited insulin-stimulated glucose uptake in mouse 3T3-L1 adipocytes. On the other hand, naringenin, a flavanone, inhibited insulin-stimulated glucose uptake through blocking PI3K activity in the cell line. ${ }^{17)}$ Therefore, in this study, we investigated the effects of flavonoids on insulin-induced glucose uptake in mouse MC3T3-G2/PA6 adipocytes using a panel of 24 flavonoids, including flavones, flavonols, isoflavones, flavanones, flavanols and flavanonols.

\section{MATERIALS AND METHODS}

Materials The flavones, flavone, apigenin, luteolin and chrysin, the flavonols, kaempferol, quercetin, rutin and morin, the isoflavones, daidzein and genistein, the flavanones, hesperetin, hesperidin and naringenin, the flavanonol, silybin, the flavanols, $(+)$-catechin and EGCG, fetal bovine serum (FBS) and insulin were purchased from SigmaAldrich Corp. (St. Louis, MO, U.S.A.). The flavone, baicalein, and the flavonols, galangin, myricetin and quercetagetin, were from Extrasynthese (Genay Cedex, France). The flavonol, fisetin, the flavanol, (-)-catechin, dexamethasone (Dex) and 1-methyl-3-isobutylxanthine (IBMX) were from Wako Pure Chemical Industries, Ltd. (Osaka, Japan). 
Theaflavins (flavanol) were from Kurita Industries (Tokyo, Japan). The structures are shown in Fig. 1. Alpha modification of Eagle's minimal medium ( $\alpha$-MEM) was from ICN Biomedicals, Inc. (Irvine, CA, U.S.A.). Kanamycin was from EMD Biosciences (Calbiochem; San Diego, CA, U.S.A.). The Akt kinase assay kit was from Upstate (Charlottesville, VA, U.S.A.). The anti-Akt1/2 antibody, anti-glucose transporter 1 (GLUT1) antibody, anti-GLUT4 antibody and monoclonal anti-phosphotyrosine antibody (pY20) were from Santa Cruz Biotechnology, Inc. (Santa Cruz, CA, U.S.A.). 2-
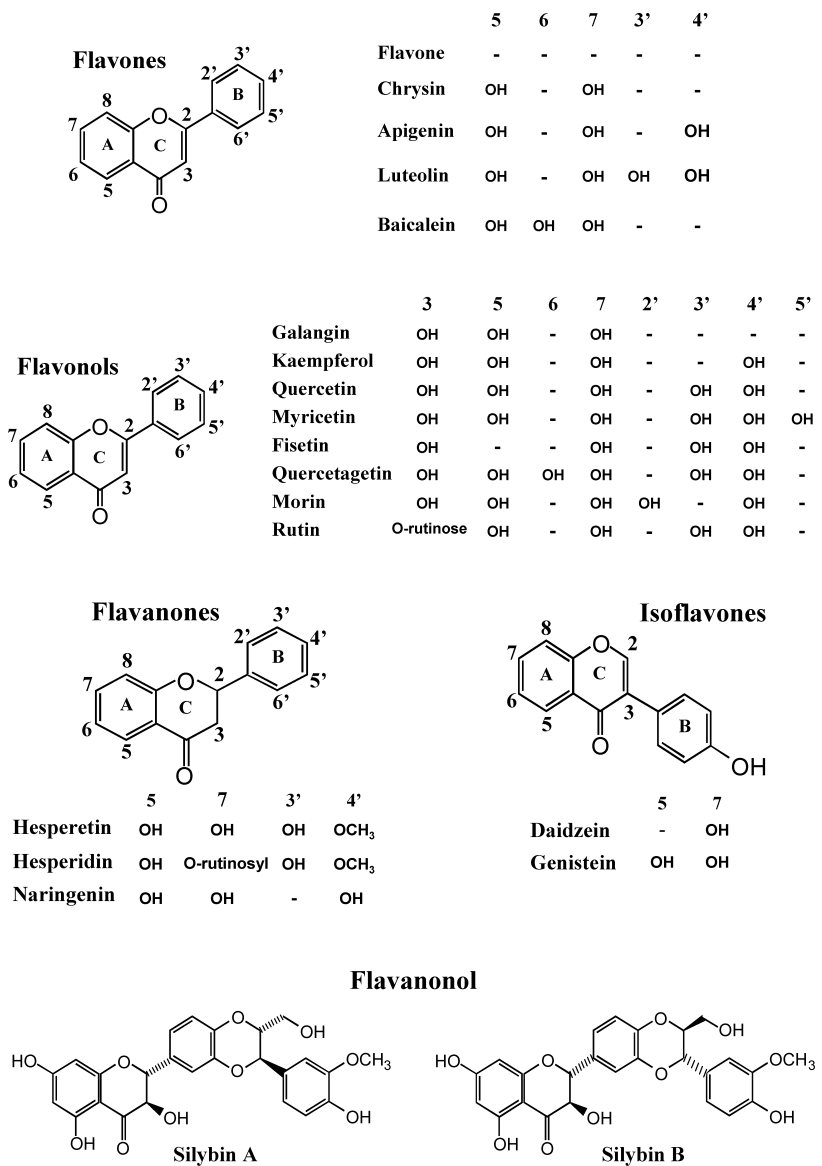

Silybin (mixture of two diastereomers)
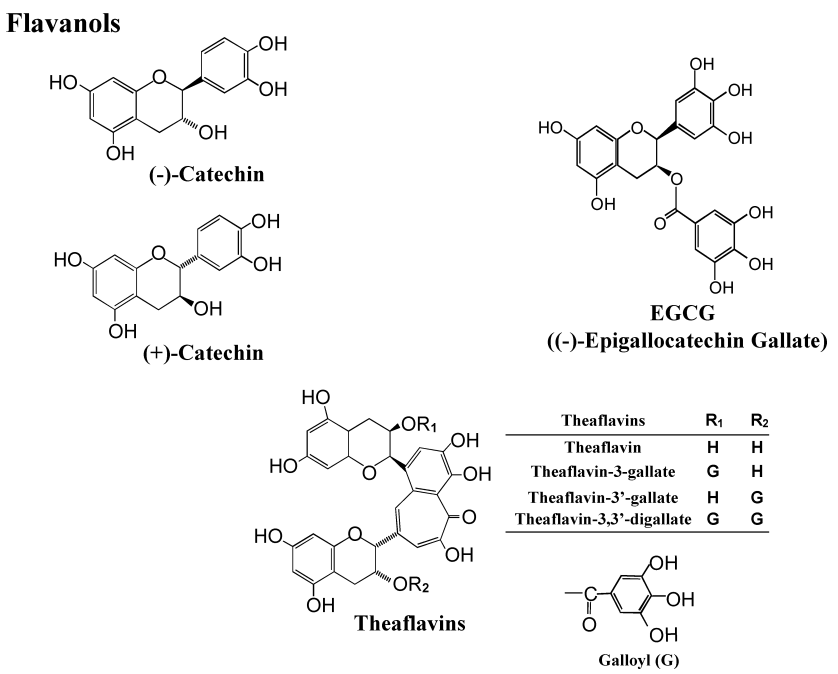

Fig. 1. Structures of Flavonoids Used in This Study
Deoxy-D- $\left[1-\mathrm{H}^{3}\right]$ glucose and $\left[\gamma_{-}{ }^{32} \mathrm{P}\right]$ ATP were purchased from Amersham Biosciences Corp. (Piscataway, NJ, U.S.A.).

Cell Culture The mouse preadipocyte cell line, MC3T3G2/PA $6,{ }^{18)}$ was maintained in $\alpha$-MEM supplemented with $10 \%$ heat-inactivated FBS and $60 \mu \mathrm{g} / \mathrm{ml}$ kanamycin in an atmosphere of $5 \% \mathrm{CO}_{2}$ at $37^{\circ} \mathrm{C}$. Differentiation was induced by treating confluent cells with $\alpha$-MEM containing $0.5 \mathrm{~mm}$ IBMX, $0.25 \mu \mathrm{M}$ Dex and 10\% FBS for $4 \mathrm{~d}$. The cells were refed with $\alpha$-MEM supplemented with $10 \%$ FBS every other day for the following $4-6 \mathrm{~d}$.

Glucose Uptake Glucose uptake was measured as described previously. ${ }^{19)}$ In brief, cells cultured in 24-well plates were incubated in $\alpha$-MEM containing $0.1 \%$ FBS for $24 \mathrm{~h}$ at $37^{\circ} \mathrm{C}$. Then the medium was changed to Krebs-Ringer phosphate (KRP) buffer and incubation was continued for $2 \mathrm{~h}$ at $37^{\circ} \mathrm{C}$. Before the cells were exposed to insulin, they were treated or not treated with the indicated concentration of each flavonoid in KRP buffer for $1 \mathrm{~h}$. After incubation with or without insulin $(1 \mu \mathrm{M})$ for $20 \mathrm{~min}, 2$-deoxy-D-[1- $\left.{ }^{3} \mathrm{H}\right]$ glucose $(0.5 \mu \mathrm{Ci}$; final conc.: $71.4 \mathrm{~nm})$ [specific activity; 14.0 $\mathrm{Ci} / \mathrm{mmol}$ (518 GBq/mmol)] was added, and incubation was continued for $5 \mathrm{~min}$. The cells were washed twice with icecold PBS and then solubilized with $0.1 \%$ SDS in $1 \mathrm{~N} \mathrm{NaOH}$. The radioactivity incorporated into the cells was measured by liquid scintillation spectroscopy.

Immunoblotting Differentiated MC3T3-G2/PA6 cells cultured in 24-well plates were incubated in $\alpha$-MEM containing $0.1 \%$ FBS for $24 \mathrm{~h}$ at $37^{\circ} \mathrm{C}$. The medium was changed to $\alpha$-MEM containing $0.1 \%$ FBS and incubation was continued for another $2-4 \mathrm{~h}$ at $37^{\circ} \mathrm{C}$. Before the cells were exposed to insulin, they were treated or not treated with each flavonoid $(10 \mu \mathrm{M})$ for $1 \mathrm{~h}$. Then, insulin $(1 \mu \mathrm{M})$ was added and incubation was continued for an additional $5 \mathrm{~min}$ at $37^{\circ} \mathrm{C}$. The cells were washed twice with ice-cold PBS and lysed in lysis buffer $(400 \mu \mathrm{l})$ [20 mM Tris-HCl, pH 7.5, $150 \mathrm{~mm} \mathrm{NaCl}, 1 \mathrm{~mm}$ ethylenediaminetetraacetic acid, $1 \mathrm{~mm}$ ethyleneglycol-bis( $\beta$-aminoethylether)- $N, N, N^{\prime}, N^{\prime}$-tetraacetic acid, $1 \%$ Triton $\mathrm{X}-100,2.5 \mathrm{~mm}$ sodium pyrophosphate, $1 \mathrm{~mm}$ $\beta$-glycerophosphate, $1 \mathrm{~mm}$ sodium orthovanadate, $5 \mu \mathrm{g} / \mathrm{ml}$ aprotinin, $5 \mu \mathrm{g} / \mathrm{ml}$ pepstatin $\mathrm{A}, 10 \mu \mathrm{g} / \mathrm{ml}$ leupeptin, $1 \mathrm{~mm}$ phenylmethylsulfonyl fluoride, $1 \mu \mathrm{M}$ microcystin LR]. The lysate was sonicated and centrifuged $(15000 \mathrm{rpm})$ for $10 \mathrm{~min}$ at $4{ }^{\circ} \mathrm{C}$. The quantity of protein in the supernatant fraction was normalized against the untreated control, and immunoprecipitation was performed with $20 \mu \mathrm{l}$ of anti-insulin receptor $\beta$-subunit antibody. The enzyme immune complex was washed three times with $0.5 \mathrm{ml}$ of lysis buffer and twice with PBS, and then $100 \mu \mathrm{l}$ of $1 \times$ SDS sample buffer $[62.5 \mathrm{~mm}$ Tris- $\mathrm{HCl}, \mathrm{pH} 6.8,2 \%(\mathrm{w} / \mathrm{v})$ sodium dodecyl sulfate, $10 \%$ glycerol, $50 \mathrm{~mm}$ dithiothreitol, $0.1 \% \quad(\mathrm{w} / \mathrm{v})$ bromophenol blue] was added. Immunoblotting analysis was performed with anti-phosphotyrosine antibody (pY20).

Differentiated 3T3-G2/PA6 cells pretreated with each flavonoid $(10 \mu \mathrm{M})$ for $1 \mathrm{~h}$ were incubated with insulin $(1 \mu \mathrm{M})$ for $20 \mathrm{~min}$ and the plasma membrane fraction was isolated as described previously. ${ }^{19)}$ The quantity of plasma membrane protein was normalized against the untreated control, and immunoblotting was performed with anti-GLUT1 and antiGLUT4 antibodies. Antibody-bound proteins were detected by fluorescence measurement (ECF Western Blotting Kit, Amersham Biosciences) and bands were analyzed with a Ty- 
phoon 9410 image analyzer (Amersham Biosciences).

Akt Kinase Assay Differentiated MC3T3-G2/PA6 cells pretreated with flavonoids $(10 \mu \mathrm{M})$ for $1 \mathrm{~h}$ were exposed to insulin $(1 \mu \mathrm{M})$ for $5 \mathrm{~min}$. The cells were lysed in $400 \mu \mathrm{l}$ of lysis buffer, and the lysate was sonicated and centrifuged. The quantity of protein in the supernatant fraction was normalized against the untreated control, and immunoprecipitation was carried out using $20 \mu \mathrm{l}$ of anti-Akt1/2 antibody (Santa Cruz). Akt activities were determined using a specific Akt substrate peptide and $\left[\gamma_{-}{ }^{32} \mathrm{P}\right]$ ATP as described previously. $^{20)}$

Statistical Analysis Statistical analysis was done using one-way analysis of variance followed by the multiple range test of Scheffe's $F$.

\section{RESULTS}

Effects of Flavonoids on Insulin-Stimulated Glucose Uptake We assessed the effect of different classes of flavonoids on insulin-induced 2-deoxy-D-[1- $\left.{ }^{3} \mathrm{H}\right]$ glucose uptake in MC3T3-G2/PA6 cells differentiated into mature adipose cells. Among the flavonoids examined at $10 \mu \mathrm{M}$, the flavones, apigenin and luteolin, and the flavonols, kaempferol, quercetin and fisetin, significantly inhibited insulin-stimulated glucose uptake (Fig. 2A). An isoflavone, genistein, a flavanonol, silybin, and the flavanols, EGCG and theaflavins, also significantly inhibited insulin-stimulated glucose uptake (Figs. 2B, C). The inhibition by these flavonoids was concentration-dependent (Figs. 2A-C). On the other hand, the flavanones, hesperetin, hesperidin and naringenin, did not show any inhibitory effect (Fig. 2B).

Effects of Flavonoids on Insulin-Stimulated Tyrosine Phosphorylation of Insulin Receptor $\boldsymbol{\beta}$-Subunit We then evaluated the effect of flavonoids $(10 \mu \mathrm{M})$ on insulin-stimulated tyrosine phosphorylation of insulin receptor $\beta$-subunit (IR- $\beta$ ). Among flavonoids that inhibited glucose uptake, luteolin significantly decreased insulin-stimulated IR- $\beta$ phosphorylation (Fig. 3A). Apigenin, kaempferol, quercetin and fisetin also tended to inhibit insulin-stimulated IR- $\beta$ phosphorylation (Fig. 3A). On the other hand, none of the isoflavones, flavanols or flavanonols, including genistein, silybin, EGCG and theaflavins, was inhibitory (Figs. 3B, C).

Effects of Flavonoids on Insulin-Stimulated Activation of the PI3K Pathway To confirm whether flavonoids that inhibited glucose uptake affect the PI3K pathway, we investigated their effects on insulin-stimulated activation of Akt, a pivotal downstream effector of PI3K. At $10 \mu \mathrm{M}$, luteolin and kaempferol significantly suppressed insulin-stimulated Akt activation (Fig. 4). In addition, apigenin, quercetin and fisetin appeared to inhibit insulin-stimulated Akt activation (Fig. 4). On the other hand, genistein, silybin, EGCG and theaflavins did not affect insulin-stimulated Akt activation (Fig. 4).

Effects of Flavonoids on Insulin-Stimulated Translocation of GLUT4 to Plasma Membrane We examined the effect of flavonoids on GLUT4 translocation to the plasma membrane induced by insulin stimulation. As shown in Fig. 5 , immunoblotting analysis with anti-GLUT4 antibody indicated that all the flavonoids $(10 \mu \mathrm{M})$ that inhibited glucose uptake also decreased the insulin-stimulated increase of GLUT4 in plasma membrane, as did wortmannin (100 nM). In contrast, the amount of GLUT1 in the plasma membrane was unaffected by insulin or any flavonoid.

\section{DISCUSSION}

We found in this study that the flavones, apigenin and luteolin, the flavonols, kaempferol, quercetin and fisetin, an isoflavone, genistein, the flavanols, EGCG and theaflavins, and a flavanonol, silybin, significantly inhibited insulin-stimulated glucose uptake in MC3T3-G2/PA6 cells differentiated into mature adipose cells. As shown in Fig. 1, the basic structure of flavonoids is comprised of two benzene rings (A- and B-ring) linked through a heterocyclic pyran or pyrone ring (C-ring) in the middle. The B-ring is usually located at the 2position of the C-ring. The subdivisions of flavonoids are primarily based on the presence of an oxy group at position 4, a double bond between carbon atoms 2 and 3 (C2-C3 double bond), and the presence of a hydroxyl group at position 3 (3$\mathrm{OH})$ of the C-ring. Flavones lack 3-OH of the C-ring. However, we found that apigenin and luteolin significantly inhibited insulin-stimulated glucose uptake, as did 3-OH-containing flavonols such as kaempferol and quercetin, suggesting that 3-OH of the C-ring is not important for inhibition of glucose uptake. The lack of inhibitory effect of rutin, which is glycosylated at position 3 of the C-ring of quercetin, may be due to low permeability into the cells, because of the hydrophilic character of $o$-rutinose. Flavones and flavonols, such as apigenin, luteolin, kaempferol, quercetin and fisetin, all of which were potent inhibitors of glucose uptake, have a hydroxyl group at position $4^{\prime}\left(4^{\prime}-\mathrm{OH}\right)$ or at both of positions $3^{\prime}$ and $4^{\prime}\left(3^{\prime}, 4^{\prime}-\mathrm{OH}\right)$ of the B-ring and a $\mathrm{C} 2-\mathrm{C} 3$ double bond. Loss of the B-ring hydroxyl group (chrysin, baicalein and galangin), or a greater degree of hydroxyl substitution (myricetin), or substitution at a different position (morin) resulted in loss of the ability to inhibit insulin-stimulated glucose uptake. Thus, it appears that the position of hydroxyl substitution $\left(4^{\prime}-\right.$ or $\left.3^{\prime}, 4^{\prime}-\mathrm{OH}\right)$ in the B-ring is important for inhibitory activity on glucose uptake. In addition, naringenin (flavanone), which lacks the $\mathrm{C} 2-\mathrm{C} 3$ double bond of apigenin, did not inhibit insulin-stimulated glucose uptake, suggesting that the $\mathrm{C} 2-\mathrm{C} 3$ double bond also plays an important role. An isoflavone, genistein, inhibited insulin-stimulated glucose uptake, while daizein, which lacks a hydroxyl group at position $5(5-\mathrm{OH})$ in the A-ring of genistein, did not. Thus, $5-\mathrm{OH}$ in the A-ring of isoflavones also seems to be involved in the inhibition of glucose uptake, though it is absent in the inhibitory flavonol, fisetin. Flavanols, $(+)$ - and $(-)$-catechin, which do not have either the oxy group at position 4 or the C2-C3 double bond, did not affect glucose uptake. The relevance of the oxy group at position 4 for inhibition of glucose uptake is not clear. However, EGCG and theaflavins, which contain the galloyl group, showed a strong inhibitory effect. Therefore, the galloyl group was considered to be important for the inhibitory effects of EGCG and theaflavins on glucose uptake. A flavanonol, silybin, significantly inhibited insulinstimulated glucose uptake, although flavanonols also lack a C2-C3 double bond in the C-ring. However, we did not examine other flavanonols here, so it is difficult to relate the inhibitory effect of silybin to its structure. As summarized in Fig. 6, the above findings indicate that the important structural features of flavonoids for inhibition of insulin-stimulated glucose uptake are as follows: 1) $4^{\prime}$ - or $3^{\prime}, 4^{\prime}-\mathrm{OH}$ on the 

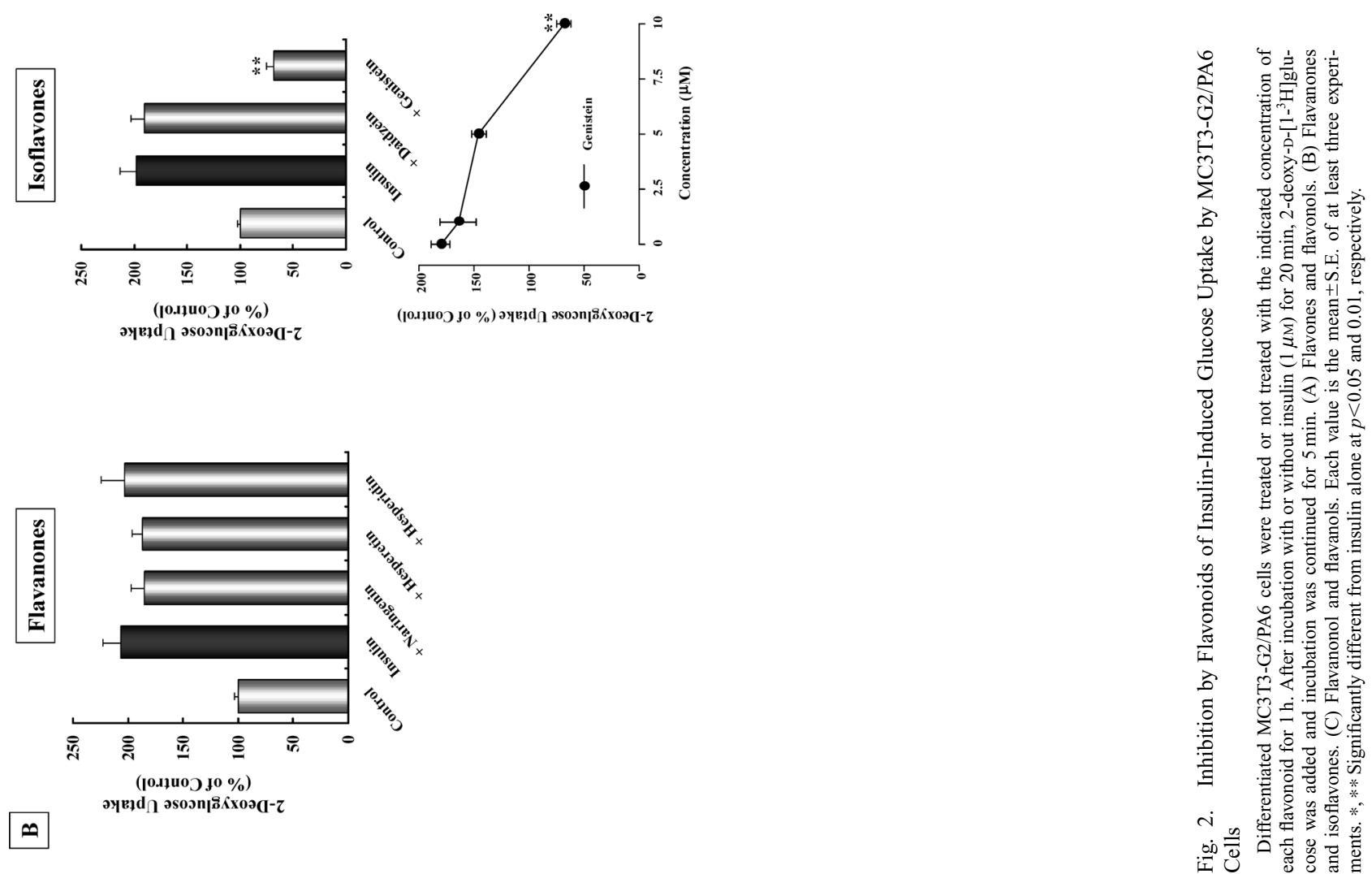

$\infty$

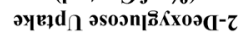
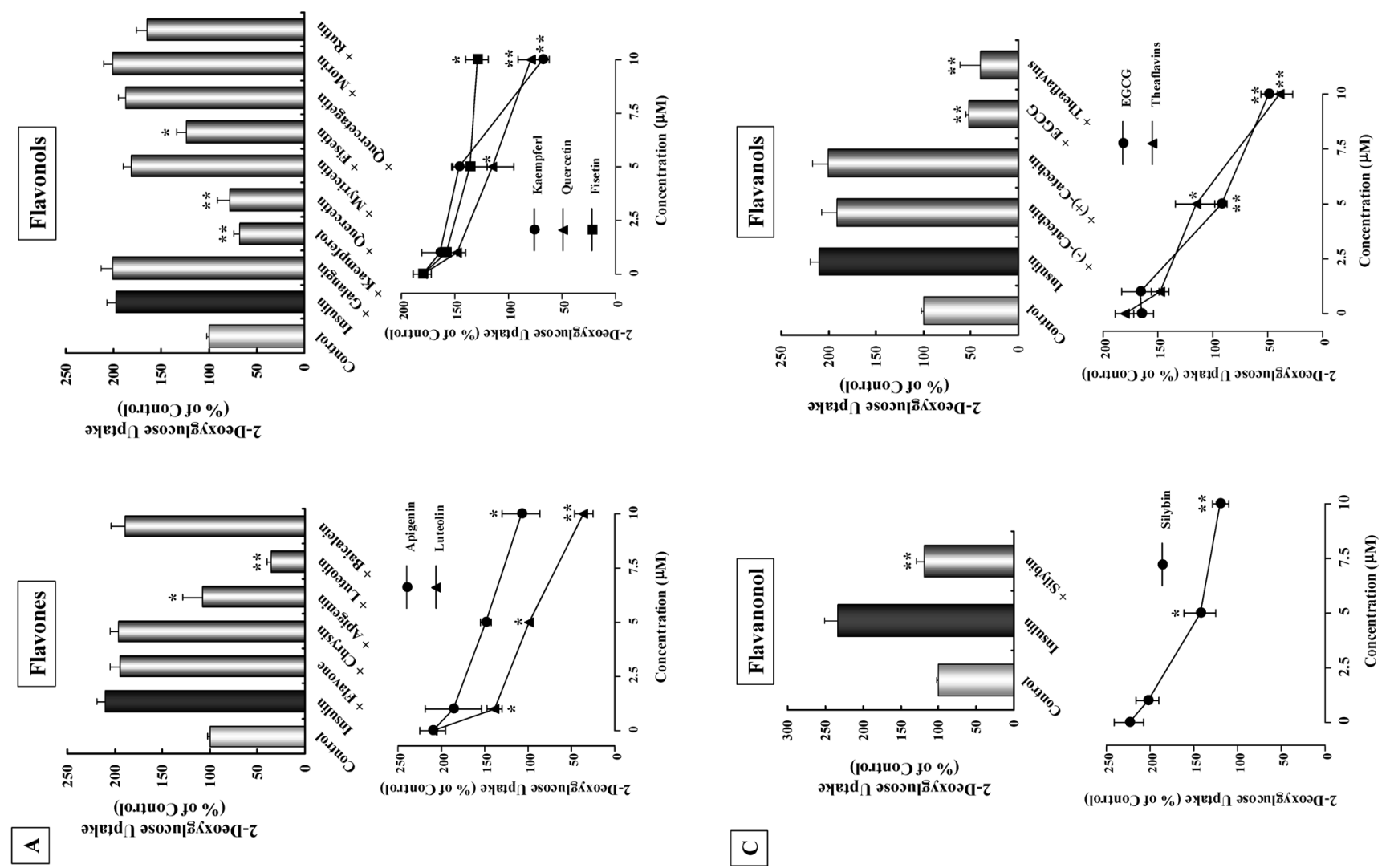
$\mathbf{A}$

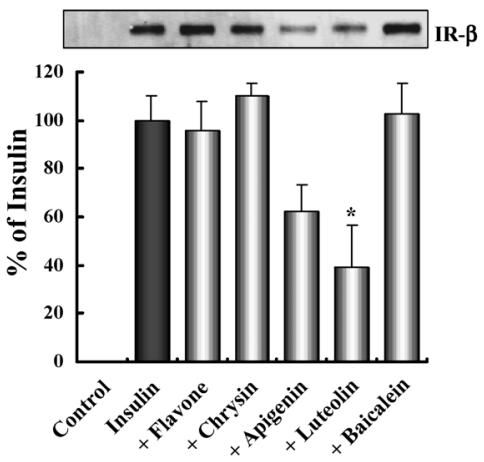

B
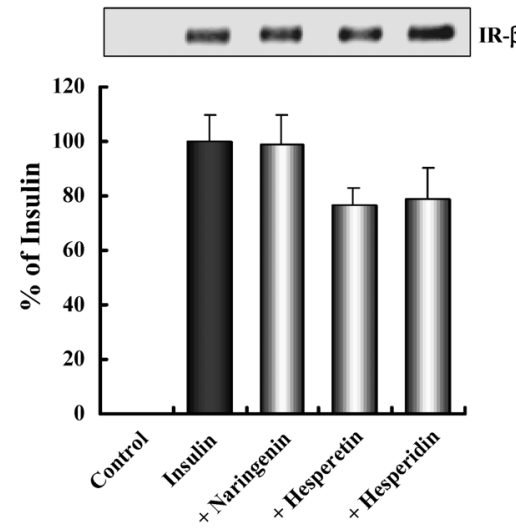

$\mathbf{C}$
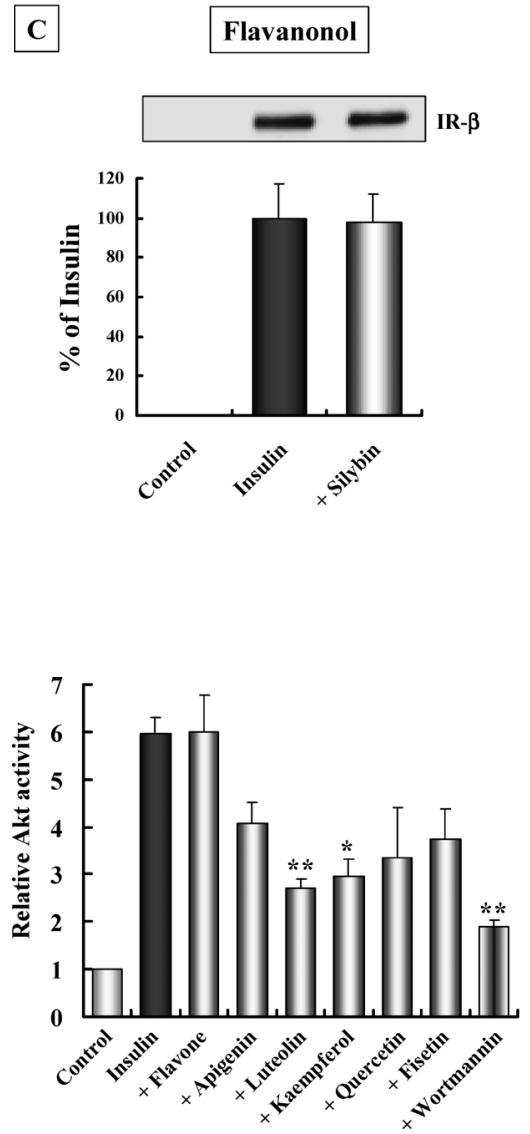
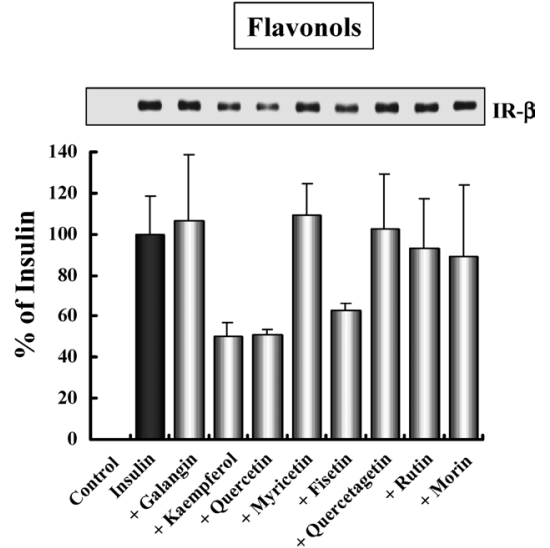

Isoflavones
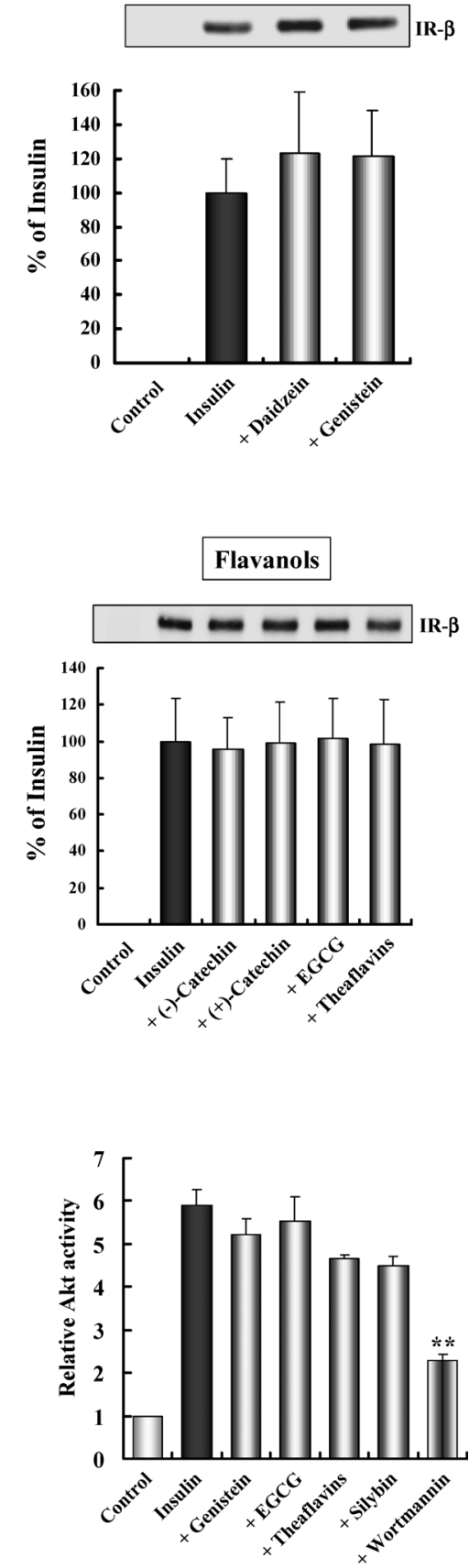

Fig. 3. Effects of Flavonoids on Insulin-Induced Tyrosine Phosphorylation of IR- $\beta$

Differentiated MC3T3-G2/PA6 cells were treated or not treated with each flavonoid $(10 \mu \mathrm{M})$ for $1 \mathrm{~h}$. After incubation with or without insulin $(1 \mu \mathrm{M})$ for $5 \mathrm{~min}$, the cells were lysed, and the lysate was immunoprecipitated with $20 \mu \mathrm{l}$ of anti-insulin receptor $\beta$-subunit antibody. The phosphorylation level of enzyme immune complex was estimated by immunoblotting with anti-phosphotyrosine antibody (pY20). (A) Flavones and flavonols. (B) Flavanones and isoflavones. (C) Flavanonol and flavanols. Each value is the mean \pm S.E. of at least three experiments. $*$ Significantly different from insulin alone at $p<0.05$.
Fig. 4. Inhibition by Flavonoids of Insulin-Induced Akt Activation

Differentiated MC3T3-G2/PA6 cells were treated or not treated with each flavonoid $(10 \mu \mathrm{M})$ or wortmannin $(100 \mathrm{~nm})$ for $1 \mathrm{~h}$. Then, the cells were incubated with or without insulin $(1 \mu \mathrm{M})$ for $5 \mathrm{~min}$. The cells were lysed, and the lysate was immunoprecipitated with anti-Akt $1 / 2$ antibody. The Akt activities were determined using a specific Akt substrate peptide and $\left[\gamma-{ }^{32} \mathrm{P}\right]$ ATP. Each value is the mean \pm S.E. of three experiments. *,** Significantly different from insulin alone at $p<0.05$ and 0.01 , respectively. 

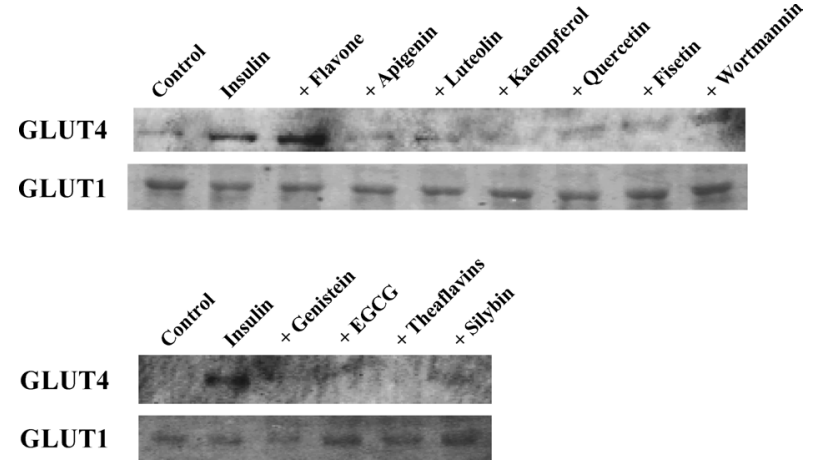

Fig. 5. Effects of Flavonoids on Insulin-Induced GLUT4 Translocation to Plasma Membrane

Differentiated MC3T3-G2/PA6 cells were treated or not treated with each flavonoid $(10 \mu \mathrm{M})$ or wortmannin $(100 \mathrm{nM})$ for $1 \mathrm{~h}$. Then, the cells were incubated with or without insulin $(1 \mu \mathrm{M})$ for $20 \mathrm{~min}$. The amount of GLUT1 and GLUT4 in plasma membrane was detected by immunoblotting with anti-GLUT1 and anti-GLUT4 antibodies.
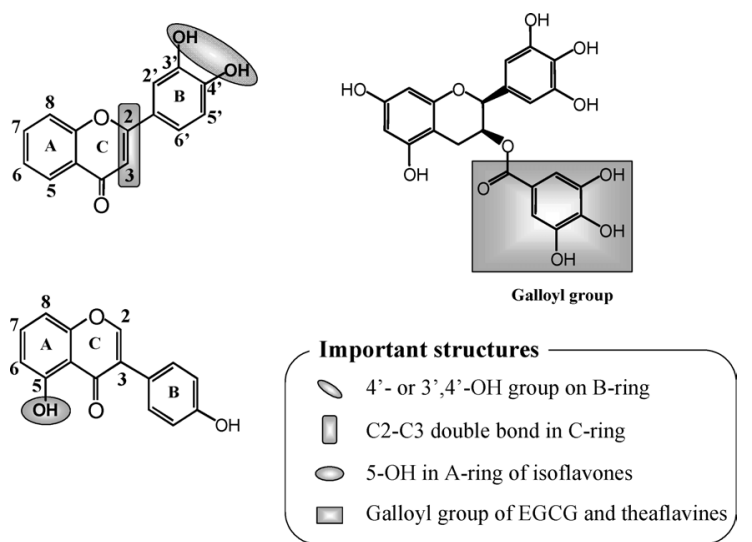

Fig. 6. Relationship between Flavonoid Structure and Glucose UptakeInhibitory Activity

Important structural features of flavonoids for cell transformation-inhibitory activity are $4^{\prime}-$ or $3^{\prime}, 4^{\prime}-\mathrm{OH}$ on the B-ring and the $\mathrm{C} 2-\mathrm{C} 3$ double bond in the C-ring in flavones and flavonols, 5-OH in the A-ring of isoflavones, and the galloyl group in EGCG and theaflavins.

B-ring and $\mathrm{C} 2-\mathrm{C} 3$ double bond in the $\mathrm{C}$-ring of flavones and flavonols, 2) 5-OH in the A-ring of isoflavones, and 3) the galloyl group in EGCG and theaflavins.

Insulin signaling is initiated by activation of IR through autophosphorylation, and this, in turn, leads to activation of the IR substrate (IRS) family and related proteins, including PI3K and its downstream targets. ${ }^{21)}$ Several reports have shown that some flavonoids inhibit RTKs. ${ }^{11,12,22-24)}$ Our results showed that luteolin significantly suppressed insulinstimulated tyrosine phosphorylation of IR- $\beta$. Apigenin, kaempferol, quercetin and fisetin, which inhibited glucose uptake, also tended to inhibit insulin-stimulated IR- $\beta$ phosphorylation. These findings suggested that the inhibition of glucose uptake by these flavones and flavonols is partly related to the suppression of IR phosphorylation. The presence of $3^{\prime}$ and $4^{\prime}-\mathrm{OH}$ on the B-ring and $\mathrm{C} 2-\mathrm{C} 3$ double bond in the $\mathrm{C}$-ring of flavones and flavonols is suggested to be critical for inhibitory activity towards protein kinases, including PI3K, PKC, myosin light chain kinase and $G$ type casein kinase. ${ }^{12,25,26)}$ However, the relationship between the structures of flavonoids and the inhibition of RTK activity is controversial. ${ }^{12,22,23)}$ Our result suggests that the structures of flavones and flavonols are also related to the inhibition of RTK of IR. On the other hand, isoflavones, flavanols, flavanones and flavanonols did not affect insulin-stimulated IR- $\beta$ phosphorylation. Therefore, the inhibition of glucose uptake by genistein, EGCG, theaflavins and silybin presumably involved other mechanism(s) than the inhibition of IR phosphorylation.

Insulin-induced glucose uptake occurs primarily through translocation of GLUT4 to the plasma membrane. Numerous studies have shown that the PI3K pathway is critical for insulin-stimulated GLUT4 translocation. ${ }^{5-9)}$ Our previous study also indicated that the PI3K/Akt pathway is closely involved in insulin-stimulated GLUT4 translocation and glucose uptake in differentiated MC-3T3-G2/PA6 cells. ${ }^{19)}$ Since several flavonoids have been reported to inhibit PI3K,,$^{11,12,20)}$ we examined the effects of flavonoids, which inhibited glucose uptake, on insulin-stimulated activation of Akt, a pivotal downstream effector of PI3K. Luteolin and kaempferol significantly inhibited insulin-stimulated Akt activation. In addition, apigenin, quercetin and fisetin also appeared to suppress insulin-stimulated Akt activation. On the other hand, genistein, EGCG, theaflavins and silybin, which did not affect IR phosphorylation, had no effect on insulin-stimulated Akt activation. Agullo et al. ${ }^{12)}$ showed that the position, number and substitution of the $\mathrm{OH}$ groups of the B-ring and the $\mathrm{C} 2-\mathrm{C} 3$ double bond of the C-ring are important factors affecting PI3K inhibition by flavonoids. They also indicated that the potent inhibitors, such as luteolin, quercetin, and myricetin, have $3^{\prime}, 4^{\prime}-\mathrm{OH}$ on the B-ring. Quercetin and its analogues also inhibit PI3K. ${ }^{27)}$ LY294002, a PI3K inhibitor, was synthesized using quercetin as a model. ${ }^{28)}$ It is likely that the flavones and flavonols inhibit Akt activation through the blocking of PI3K activation. However, the inhibition pattern of Akt activation by these flavones and flavonols is similar to that of IR phosphorylation, suggesting that the inhibition of Akt activation by these flavones and flavonols is involved in blocking of insulin signaling by suppression of IR phosphorylation. We and others have shown that flavonoids, such as quercetin, myricetin, EGCG and theaflavins, inhibited PI3K activation. ${ }^{11,12,20,29,30)}$ However, myricetin did not inhibit insulin-stimulated glucose uptake in this study, and the treatment has been reported to increase phosphorylation of IR, IRS-1 and Akt in soleus muscle of fluctose chow-fed rats and obese Zucker rats. ${ }^{31,32)}$ Although quercetin has been shown to compete with ATP at its binding site, ${ }^{12,27)}$ the treatment with a concentration at $10 \mu \mathrm{M}$ with mouse epidermal JB6 cells did not directly inhibit PI3K activation. ${ }^{29)}$ EGCG is known to inhibit gluconeogenesis through activation of PI3K-dependent pathway in hepatocytes. ${ }^{33)}$ EGCG also stimulates activation of endothelial nitric oxide synthase (eNOS) through activation of PI3K/Akt pathway. ${ }^{34)}$ These findings suggest that the modification of PI3K activation by flavonoids is different for concentrations, cell types, and classes of stimulants.

Interestingly, we found that all the flavonoids that inhibited glucose uptake suppressed insulin-stimulated GLUT4 translocation into plasma membrane. This result is consistent with a finding in mouse 3T3-L1 adipocytes treated with genistein. ${ }^{15)}$ Strobel et al. ${ }^{16)}$ also suggested that myricetin, quercetin and catechin-gallate inhibit glucose uptake through direct interaction with GLUT4. It is suggested that the inhibition of glucose uptake by genistein, EGCG, theaflavins and silybin occurs through blocking of insulin-stimulated 
GLUT4 translocation to the plasma membrane. Furthermore, the inhibition of glucose uptake by the flavones and flavonols also seems to be involved in blocking of the GLUT4 translocation in addition to the suppression of IR phosphorylation.

In this study, we found that different classes of flavonoids inhibit insulin-induced glucose uptake in MC3T3-G2/PA6 adipose cells. The important structural features of flavonoids for inhibition of insulin-stimulated glucose uptake are $4^{\prime}$ - or $3^{\prime}, 4^{\prime}-\mathrm{OH}$ on the B-ring and the $\mathrm{C} 2-\mathrm{C} 3$ double bond in the $\mathrm{C}$ ring of flavones and flavonols, the 5-OH in the A-ring of isoflavones, and the galloyl group in EGCG and theaflavins. The inhibitory mechanism of flavonoids on insulin-stimulated glucose uptake is suggested to be involved in blocking of GLUT4 translocation to the plasma membrane. Thus, the structures of flavonoids may be important for the interaction with GLUT4. In addition, the flavones and flavonols, apigenin, luteolin, kaempferol, quercetin and fisetin, appeared to inhibit Akt activation through the suppression of IR phosphorylation. Because PI3K/Akt pathway is not only involved in glucose transport but also in glucogen synthesis, protein synthesis and cell survival, ${ }^{35-37)}$ the results in this study explain, in part, structure-activity relationship of flavonoids for modulation of insulin's action.

Acknowledgments This work was supported in part by Grant-in-Aid for Scientific Research from the Ministry of Education, Culture, Sports, Science and Technology of Japan.

\section{REFERENCES}

1) Hunter S. J., Garvey W. T., Am. J. Med., 105, 331-335 (1998)

2) James D. E., Strube M., Mueckler M., Nature (London), 338, 83-87 (1989).

3) Ottensmeyer F. P., Beniac D. R., Luo R. Z., Yip C. C., Biochemistry, 39, 12103-12112 (2000).

4) Ellis L., Clauser E., Morgan D. O., Edery M., Roth R. A., Rutter W. J., Cell, 45, 721-732 (1986).

5) Lund S., Pryor P. R., Ostergaard S., Schmitz O., Pedersen O., Holman G. D., FEBS Lett., 425, 472-474 (1998).

6) Tsakiridis T., McDowell H. E., Walker T., Downes C. P., Hundal H. S., Vranic M., Klip A., Endocrinology, 136, 4315-4322 (1995).

7) Tanti J. F., Gremeaux T., Grillo S., Calleja V., Klippel A., Williams L. T., Van Obberghen E., Le Marchand-Brustel Y., J. Biol. Chem., 271, $25227-25232$ (1996)

8) Kotani K., Carozzi A. J., Sakaue H., Hara K., Robinson L. J., Clark S. F., Yonezawa K., James D. E., Kasuga M., Biochem. Biophys. Res. Commun., 209, 343-348 (1995).

9) Sakaue H., Ogawa W., Takata M., Kuroda S., Kotani K., Matsumoto M., Sakaue M., Nishio S., Ueno H., Kasuga M., Mol. Endocrinol., 11, $1552-1562$ (1997).
10) Crozier A., Burns J., Aziz A. A., Stewart A. J., Rabiasz H. S., Jenkins G. I., Edwards C. A., Lean M. E., Biol. Res., 33, 79-88 (2000).

11) Middleton E., Jr., Kandaswami C., Theoharides T. C., Pharmacol Rev., 52, 673-751 (2000).

12) Agullo G., Gamet-Payrastre L., Manenti S., Viala C., Remesy C., Chap H., Payrastre B., Biochem. Pharmacol., 53, 1649-1657 (1997).

13) Ferriola P. C., Cody V., Middleton E., Jr., Biochem. Pharmacol., 38, 1617-1624 (1989).

14) Williams R. J., Spencer J. P., Rice-Evans C., Free Radic. Biol. Med., 36, 838-849 (2004).

15) Bazuine M., van den Broek P. J., Maassen J. A., Biochem. Biophys. Res. Commun., 326, 511-514 (2005).

16) Strobel P., Allard C., Perez-Acle T., Calderon R., Aldunate R., Leighton F., Biochem. J., 386(Pt 3), 471-478 (2005).

17) Harmon A. W., Patel Y. M., Biochem. Biophys. Res. Commun., 305 229-234 (2003).

18) Kodama H. A., Amagai Y., Koyama H., Kasai S., J. Cell Physiol., 112 83-88 (1982).

19) Akiba T., Yaguchi K., Tsutsumi K., Nishioka T., Koyama I., Nomura M., Yokogawa K., Moritani S., Miyamoto K., Biochem. Pharmacol., 68, 1929-1937 (2004).

20) Nomura M., Kaji A., He Z., Ma W. Y., Miyamoto K., Yang C. S., Dong Z., J. Biol. Chem., 276, 46624-46631 (2001).

21) Saltiel A. R., Kahn C. R., Nature (London), 414, 799-806 (2001)

22) Huang Y. T., Hwang J. J., Lee P. P., Ke F. C., Huang J. H., Huang C. J., Kandaswami C., Middleton E., Jr., Lee M. T., Br. J. Pharmacol., 128, 999-1010 (1999).

23) Hagiwara M., Inoue S., Tanaka T., Nunoki K., Ito M., Hidaka H., Biochem. Pharmacol., 37, 2987-2992 (1988).

24) Akiyama T., Ishida J., Nakagawa S., Ogawara H., Watanabe S., Itoh N., Shibuya M., Fukami Y., J. Biol. Chem., 262, 5592-5595 (1987).

25) Cochet C., Feige J. J., Pirollet F., Keramidas M., Chambaz E. M., Biochem. Pharmacol., 31, 1357-1361 (1982).

26) Jinsart W., Ternai B., Polya G. M., Biol. Chem. Hoppe Seyler, 372, 819-827 (1991)

27) Matter W. F., Brown R. F., Vlahos C. J., Biochem. Biophys. Res. Commun., 186, 624-631 (1992).

28) Vlahos C. J., Matter W. F., Hui K. Y., Brown R. F., J. Biol. Chem., 268 $5241-5248$ (1994).

29) Ichimatsu D., Nomura M., Nakamura S., Moritani S., Yokogawa K., Kobayashi S., Nishioka T., Miyamoto K.-I., Mol. Carcinog., 46, 436445 (2007).

30) Walker E. H., Pacold M. E., Perisic O., Stephens L., Hawkins P. T., Wymann M. P., Williams R. L., Mol. Cell, 6, 909-919 (2000).

31) Liu I.-M., Tzeng T.-F., Liou S.-S., Lan T.-W., Life Sci., 81, 14791488 (2007).

32) Liu I.-M., Tzeng T.-F., Liou S.-S., Lan T.-W., Planta Med., 73, 1054 1060 (2007).

33) Waltner-Law M. E., Wang X. L., Law B. K., Hall R. K., Nawano M., Granner D. K., J. Biol. Chem., 277, 34933-34940 (2002).

34) Kim J., Formoso G., Li Y., Potenza M. A., Marasciulo F. L., Montagnani M., Quon M. J., J. Biol. Chem., 282, 13736-13745 (2007).

35) Hajduch E., Litherland G. J., Hundal H. S., FEBS Lett., 492, 199-203 (2001).

36) Proud C. G., Biochem. Soc. Trans., 34, 213-216 (2006)

37) Van der Heide L. P., Ramakers G. M., Smidt M. P., Prog. Neurobiol., 79, 205-221 (2006). 